\title{
(2) OPEN ACCESS \\ Endovascular mechanical thrombectomy and stenting in a case of central vein thrombosis
}

\author{
Rajesh Vijayvergiya 지, ${ }^{1}$ Navjyot Kaur 지, ${ }^{1}$ Saroj K Sahoo, ${ }^{1}$ Ashish Sharma ${ }^{2}$
}

${ }^{1}$ Cardiology, Post Graduate Institute of Medical Education and Research, Chandigarh, India ${ }^{2}$ Renal Transplant Surgery, Post Graduate Institute of Medical Education and Research, Chandigarh, India

Correspondence to

Professor Rajesh Vijayvergiya; rajeshvijay999@hotmail.com

Accepted 20 October 2020

\section{SUMMARY}

Central vein stenosis and thrombosis are frequent in patients on haemodialysis for end-stage renal disease. Its management includes anticoagulation, systemic or catheter-directed thrombolysis, mechanical thrombectomy and percutaneous transluminal angioplasty (PTA). Use of mechanical thrombectomy in central vein thrombosis has been scarcely reported. We hereby report a case of right brachiocephalic vein thrombosis with underlying stenosis, which was successfully treated by mechanical thrombectomy followed by PTA and stenting. The patient had a favourable 10 months of follow-up.

\section{BACKGROUND}

The functional access site for haemodialysis is of utmost importance in patients with end-stage renal disease (ESRD). These patients usually undergo recurrent central vein cannulations for haemodialysis, before permanent arteriovenous (AV) fistula formation. Repeated cannulations and turbulence of high flow during dialysis cause endothelial injury, leading to venous stenosis and thrombosis. ${ }^{12}$ The cornerstone of treatment for central vein thrombosis includes anticoagulation, systemic or catheter-directed thrombolysis and mechanical thrombectomy. Mechanical thrombectomy is routinely used for lower limb and peripheral vein thrombosis, ${ }^{3}$ but its use in central vein thrombosis is scarce. We hereby report a case of central vein stenosis (CVS) with associated thrombosis, which was successfully treated by mechanical thrombectomy, followed by percutaneous transluminal angioplasty (PTA) and stenting.

\section{CASE PRESENTATION}

A 56-year-old hypertensive, diabetic man with ESRD underwent right radiocephalic AV fistula for haemodialysis. He had a history of recurrent bilateral internal jugular vein cannulations for haemodialysis. Two weeks after the AV fistula creation, he presented with gradual onset, progressively increasing swelling of the right upper limb. On examination, he had gross swelling and redness of the right upper limb.

Limited 2021. Re-use permitted under CC BY-NC. No commercial re-use. See rights and permissions. Published by BMJ.

To cite: Vijayvergiya $R$ Kaur N, Sahoo SK, et al. BMJ Case Rep 2021;14:e236508 doi:10.1136/bcr-2020

236508

\section{INVESTIGATIONS}

CT venography revealed thrombotic total occlusion of the right brachiocephalic vein (BCV). He was considered for PTA of occluded right BCV. Venous access via the right basilic and right femoral vein was taken. Venogram revealed complete occlusion of right $\mathrm{BCV}$ at the level of superior vena cava (figure $1 \mathrm{~A}, \mathrm{~B}$ ).

\section{TREATMENT}

The occluded segment was crossed with a 0.035 " hydrophilic glidewire (Terumo Medical Corporation, Tokyo, Japan) through right basilic access, and dilated with a $10 \times 40 \mathrm{~mm}$ peripheral balloon (Cooks Medical, Bloomington, Indiana, USA) (figure 1C). Post-PTA, there was a significant thrombus load in the BCV (figure 1D, black arrow). An 8 French $(\mathrm{F})$ mechanical thrombectomy catheter (AngioJet Zelante peripheral thrombectomy system, Boston Scientific, Natick, Massachusetts, USA) was advanced to right BCV using 9F femoral access and repeated runs of mechanical thrombectomy was performed for a total of $6 \mathrm{~min}$ (figure $2 \mathrm{~A}$, black arrow). A flow could be achieved through the right $\mathrm{BCV}$ with minimal residual thrombus load in it (figure 2B, black arrow). The procedure was stopped and he was put on heparin infusion for the next 72 hours. The patient remained haemodynamically stable without any drop in systemic saturation throughout the procedure and later in the coronary care unit. There was a partial relief in right upper limb swelling. A repeat venogram after 72 hours revealed residual narrowing of $\mathrm{BCV}$ at its proximal end, without any thrombus (figure $2 \mathrm{C}$, black arrow). The lesion was further dilated with a $12 \times 40 \mathrm{~mm}$ peripheral balloon (Cooks Medical). As there was a repetitive elastic recoil of the dilated segment, a $14 \times 60 \mathrm{~mm}$ self-expanding stent (Epic stent, Boston Scientific) was deployed across it. A brisk flow was achieved in the right BCV (figure 2D).

\section{OUTCOME AND FOLLOW-UP}

The patient had a marked decrease in right upper limb swelling over the next 24 hours. He was discharged on dual antiplatelet therapy (aspirin and clopidogrel), along with vitamin $\mathrm{K}$ antagonist (warfarin) for the next 2 months. Subsequently, he was continued on aspirin and warfarin for another 6 months, followed by aspirin for an indefinite period. Regular haemodialysis could be started through the right radio-cephalic AV fistula, after 3 weeks of intervention. His AV fistula remained functional during 10 months of follow-up, without any signs of venous obstruction.

\section{DISCUSSION}

The CVS is mostly seen in patients who were initiated on maintenance haemodialysis through a central vein catheter. It is usually attributed to dialysis catheter induced injury or sometimes because 

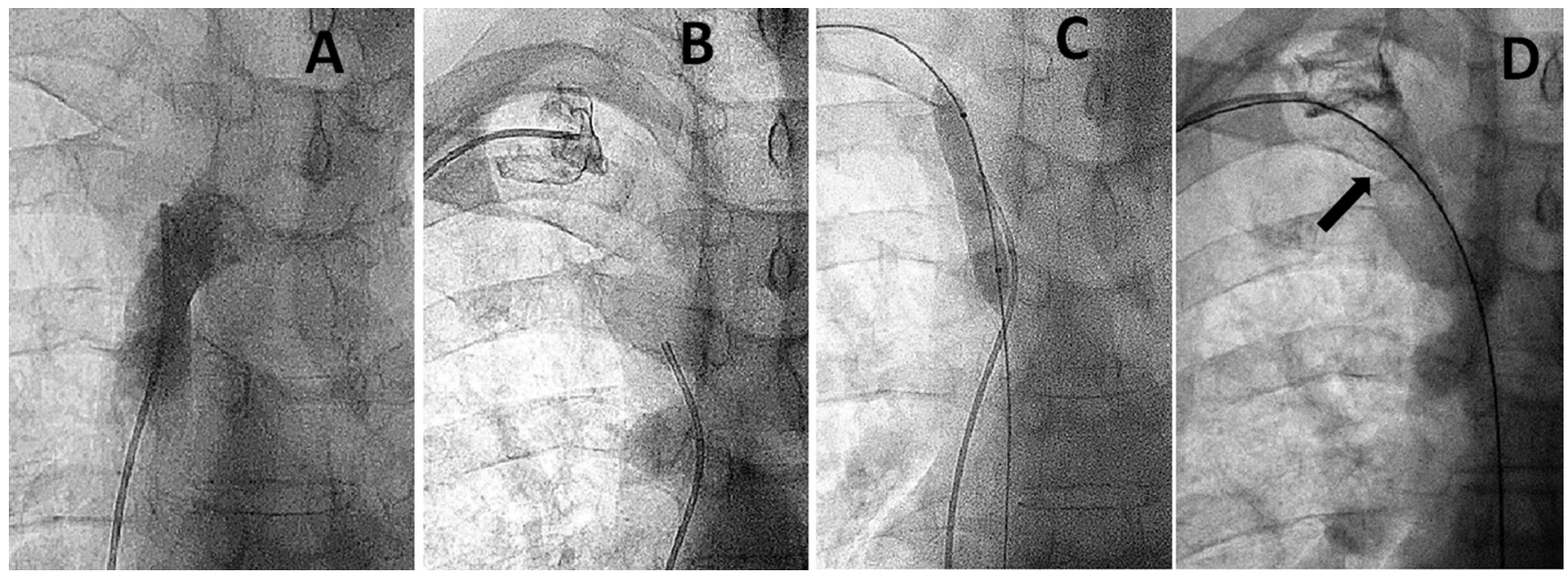

Figure 1 Venogram via the right femoral vein (A) and right basilic vein (B) showed occluded right brachiocephalic vein (BCV). The occluded segment was dilated with a $10 \times 40 \mathrm{~mm}$ peripheral balloon (C). Postdilatation, there was a significant thrombus in BCV (D, black arrow).

of de novo disease. ${ }^{4}$ Its clinical presentation is ambiguous as significant venous collaterals compensate for the blood return and prevent venous congestion. ${ }^{5}$ However, once an AV fistula is created, a large amount of blood flowing across the collaterals decompensates the venous system resulting in venous hypertension, swelling of the neck and upper limbs and failure of the AV fistula. ${ }^{5}$ The index case had asymptomatic pre-existing BCV stenosis as demonstrated on venous angiography (figure $2 \mathrm{C}$ ), which became symptomatic following the creation of AV fistula. Endothelial injury/dysfunction due to recurrent cannulations, venous stenosis and sluggish blood flow across the stenosed segment predisposes to thrombosis. ${ }^{12}$

Management of thrombotic occlusion such as in the index case requires anticoagulation, systemic or catheter-directed thrombolysis or mechanical thrombectomy. ${ }^{3}$ Systemic or catheter-directed thrombolysis in such cases has a risk of bleeding complications and pulmonary thromboembolism. ${ }^{7}$ Mechanical thrombectomy can be a safe and effective alternative in such cases. ${ }^{8}$ We used the rheolytic mechanical thrombectomy system in the index case, which acts on the principle of local injection of heparinised saline at a high velocity to macerate and fragment the thrombus, along with its aspiration. ${ }^{910}$ The complications associated with mechanical thrombectomy devices include vessel dissection/ perforation, thrombus embolisation, intravascular haemolysis, acute kidney injury and very rarely acute pancreatitis. ${ }^{10} 11$ However, the index case did not have any such complications.

The rheolytic thrombectomy system (Angiojet) was first approved in 1996 for AV fistula graft thrombectomy ${ }^{12}$ and now routinely used during the percutaneous coronary intervention ${ }^{13} 14$ and lower limb venous thrombosis. ${ }^{15}$ However, the literature about the use of rheolytic thrombectomy system for central vein thrombosis is scarce and remains an off label indication. ${ }^{16}$ The first successful use of this system to treat superior vena cava (SVC) syndrome was reported in a child after orthotopic heart transplant in year 2016. ${ }^{17}$ Ramjit et al described the successful use of rheolytic thrombectomy in SVC syndrome in a woman with lung malignancy in year 2019. ${ }^{16}$

The index case had marked improvement in thrombus load following mechanical thrombectomy, which further improved following 72 hours of heparin infusion. The CVS stenting is recommended for failed angioplasty, following suboptimal results of balloon angioplasty and for repeat interventions. ${ }^{18}$ We did BCV stenting because of $>50 \%$ recoil of the vein after balloon dilatation. There is no clear recommendation about
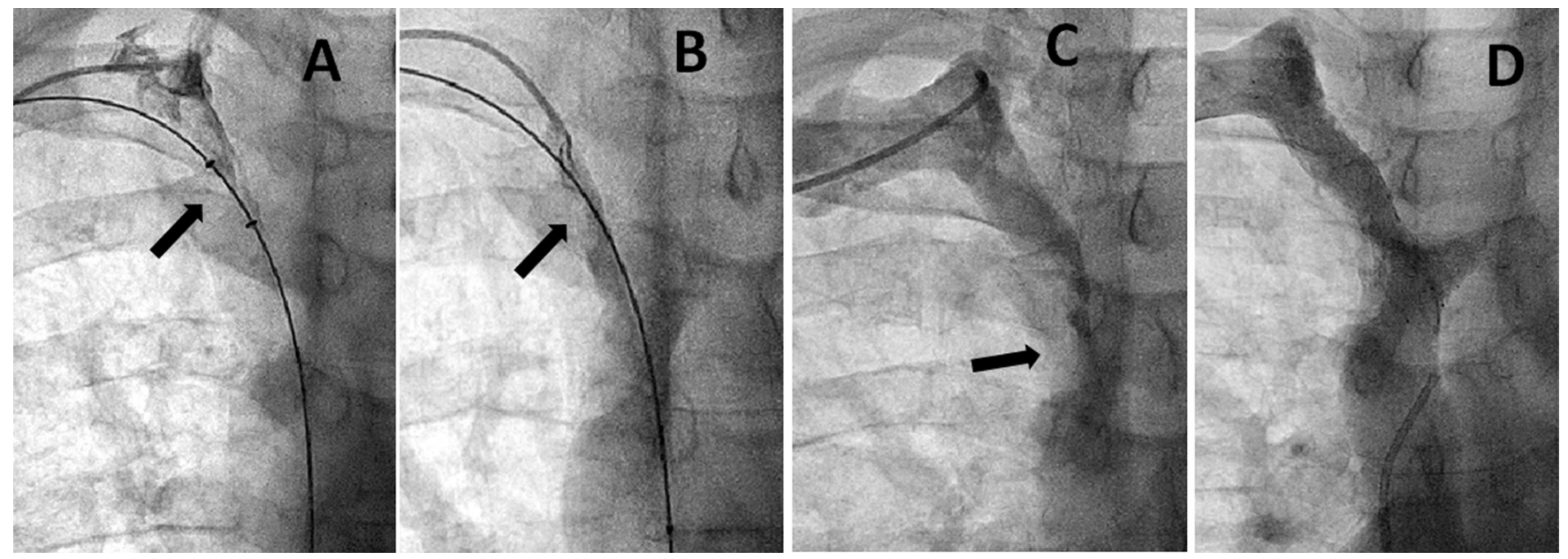

Figure 2 Mechanical thrombectomy catheter into brachiocephalic vein (BCV) (A, black arrow). Postmechanical thrombectomy, there is a significant decrease in thrombus burden (B, black arrow). After 72 hours of heparin infusion, repeat venogram showed proximal stenosis of BCV (C, black arrow), and no thrombus. Following the deployment of a $14 \times 60 \mathrm{~mm}$ self-expanding stent, there was a brisk flow in BCV (D). 
the type and duration of antithrombotic therapy following venous stenting, hence its decision is based on the thrombotic and bleeding risk of an individual patient and experience of the interventionist. ${ }^{19} 20$ We continued dual antiplatelet therapy along with oral anticoagulation for initial 2 months to prevent stent thrombosis and possible endothelisation of the stent. Later, we continued single antiplatelet therapy, that is, aspirin for an indefinite period after 8 months of intervention. These patients frequently require multiple and repetitive CVS interventions despite PTA and stenting, hence a regular long term follow-up is required to assess the venous patency. ${ }^{21}$

In conclusion, we hereby describe a case of upper limb CVS with thrombotic occlusion, which was successfully managed with mechanical thrombectomy and primary stenting. The patient had favourable clinical outcomes at 10 months of follow-up.

\section{Patient's perspective}

I am a kidney patient who is dependent on dialysis for the last 2 years. I have got fistula made in the right arm in last week of November 2019; following which I developed swelling and redness of right arm. CT scan showed a blocked vein of right arm for which I underwent treatment and stenting. Presently, I have no swelling in the right arm and I am undergoing dialysis for fistula in the right arm.

Learning points

- Patients with the end-stage renal disease with recurrent central vein cannulations for haemodialysis are prone to central vein stenosis and thrombosis.

- Management of central vein thrombosis includes anticoagulation, systemic or catheter-directed thrombolysis, mechanical thrombectomy and percutaneous transluminal angioplasty.

- Mechanical thrombectomy is a safe and effective procedure in patients with venous thrombosis, having a large thrombus burden.

- We describe a case of brachiocephalic vein thrombosis with underlying stenosis, which was successfully treated by rheolytic mechanical thrombectomy followed by stenting.

- Postintervention treatment includes anticoagulation and antiplatelet therapy. Regular long term surveillance is a must to access the patency of the venous stent.

Acknowledgements The authors would like to thank Dr Ganesh Kasinadhuni, Department of Cardiology, PGIMER and Dr Sarabjeet Singh, Department of Renal Transplant Surgery, PGIMER for their help and support.

Contributors RV involved in planning, conceptualisation, methodology, supervision and final review and editing. NK and SKS contributed to data collection, writing and original draft preparation. AS involved in planning, conceptualisation and methodology.

Funding The authors have not declared a specific grant for this research from any funding agency in the public, commercial or not-for-profit sectors.

Competing interests None declared.

Patient consent for publication Obtained.
Provenance and peer review Not commissioned; externally peer reviewed.

Open access This is an open access article distributed in accordance with the Creative Commons Attribution Non Commercial (CC BY-NC 4.0) license, which permits others to distribute, remix, adapt, build upon this work non-commercially, and license their derivative works on different terms, provided the original work is properly cited and the use is non-commercial. See: http://creativecommons.org/ licenses/by-nc/4.0/.

\section{ORCID iDs}

Rajesh Vijayvergiya http://orcid.org/0000-0001-5250-4735

Navjyot Kaur http://orcid.org/0000-0002-8392-0798

\section{REFERENCES}

1 Taal MW, Chesterton LJ, McIntyre CW. Venography at insertion of tunnelled internal jugular vein dialysis catheters reveals significant occult stenosis. Nephrol Dial Transplant 2004;19:1542-5.

2 Forauer AR, Theoharis C. Histologic changes in the human vein wall adjacent to indwelling central venous catheters. J Vasc Interv Radiol 2003;14:1163-8.

3 Engelberger RP, Kucher N. Management of deep vein thrombosis of the upper extremity. Circulation 2012;126:768-73.

4 Oguzkurt L, Tercan F, Yildirim S, et al. Central venous stenosis in haemodialysis patients without a previous history of catheter placement. Eur J Radiol 2005:55:237-42.

5 Surratt RS, Picus D, Hicks ME, et al. The importance of preoperative evaluation of the subclavian vein in dialysis access planning. AJR Am J Roentgenol 1991;156:623-5.

6 Levit RD, Cohen RM, Kwak A, et al. Asymptomatic central venous stenosis in hemodialysis patients. Radiology 2006;238:1051-6.

7 Castaneda F, Li R, Young K, et al. Catheter-directed thrombolysis in deep venous thrombosis with use of reteplase: immediate results and complications from a pilot study. J Vasc Interv Radiol 2002;13:577-80.

8 Ansel GM, George BS, Botti CF, et al. Rheolytic thrombectomy in the management of limb ischemia: 30-day results from a multicenter registry. J Endovasc Ther 2002;9:395-402.

9 Kasirajan K, Gray B, Ouriel K. Percutaneous AngioJet thrombectomy in the management of extensive deep venous thrombosis. J Vasc Interv Radiol 2001;12:179-85.

10 Lee MS, Singh V, Wilentz JR, et al. Angio Jet thrombectomy. J Invasive Cardiol 2004;16:587-91.

11 Danetz JS, McLafferty RB, Ayerdi J, et al. Pancreatitis caused by rheolytic thrombolysis: an unexpected complication. J Vasc Interv Radiol 2004;15:857-60.

12 US Food and Drug Administration (1996) Possis AngioJet $®$ rapid Thrombectomy system. FDA 510(k) Premarket Notification: 20-25. Available: https://www.accessdata. fda.gov/scripts/cdrh/cfdocs/cfPMN/pmn.cfm?ID=K960970

13 Antoniucci D, Valenti R, Migliorini A, et al. Comparison of rheolytic thrombectomy before direct infarct artery stenting versus direct stenting alone in patients undergoing percutaneous coronary intervention for acute myocardial infarction. Am J Cardiol 2004:93:1033-5.

14 Elgendy AY, Elgendy IY, Mahmoud AN, et al. Long-Term outcomes with aspiration thrombectomy for patients undergoing primary percutaneous coronary intervention: a meta-analysis of randomized trials. Clin Cardiol 2017;40:534-41.

15 Garcia MJ, Lookstein R, Malhotra R, et al. Endovascular management of deep vein thrombosis with Rheolytic thrombectomy: final report of the prospective multicenter pearl (peripheral use of AngioJet Rheolytic thrombectomy with a variety of catheter lengths) registry. J Vasc Interv Radiol 2015;26:777-85.

16 Ramjit A, Chen J, Konner $M$, et al. Treatment of superior vena cava syndrome using AngioJet ${ }^{\mathrm{TM}}$ thrombectomy system. CVIR Endovasc 2019;2:28.

17 Sessions KL, Anderson JH, Johnson JN, et al. AngioJet ${ }^{\text {TM }}$ thrombolysis of SVC thrombosis after orthotopic heart transplantation: A case report. Pediatr Transplant 2016;20:723-6.

18 Vascular Access Work Group. Clinical practice guidelines for vascular access. Am J Kidney Dis 2006;48 Suppl 1:S248-73

19 Milinis K, Thapar A, Shalhoub J, et al. Antithrombotic therapy following venous stenting: international Delphi consensus. Eur J Vasc Endovasc Surg 2018;55:537-44.

20 Eijgenraam $\mathrm{P}$, ten Cate $\mathrm{H}$, ten Cate-Hoek AJ. Venous stenting after deep venous thrombosis and antithrombotic therapy: a systematic review. Reviews in Vascular Medicine 2014;2:88-97.

21 Bakken AM, Protack CD, Saad WE, et al. Long-Term outcomes of primary angioplasty and primary stenting of central venous stenosis in hemodialysis patients. J Vasc Surg 2007:45:776-83. 
Copyright 2021 BMJ Publishing Group. All rights reserved. For permission to reuse any of this content visit https://www.bmj.com/company/products-services/rights-and-licensing/permissions/

BMJ Case Report Fellows may re-use this article for personal use and teaching without any further permission.

Become a Fellow of BMJ Case Reports today and you can:

- Submit as many cases as you like

- Enjoy fast sympathetic peer review and rapid publication of accepted articles

- Access all the published articles

Re-use any of the published material for personal use and teaching without further permission

Customer Service

If you have any further queries about your subscription, please contact our customer services team on +44 (0) 2071111105 or via email at support@bmj.com.

Visit casereports.bmj.com for more articles like this and to become a Fellow 